Article

\title{
Preparation and Photoluminescence of Transparent Poly(methyl methacrylate)-Based Nanocomposite Films with Ultra-High-Loading Pendant ZnS Quantum Dots
}

\author{
Jinku $\mathrm{Xu}$ * and Dongmei Li \\ Biomaterials and Drug Delivery Laboratory, School of Chemistry and Pharmaceutical Engineering, \\ Qilu University of Technology (Shandong Academy of Sciences), Jinan 250353, China; lidongmei0126@126.com \\ * Correspondence: jkxu2003@126.com or xujk@qlu.edu.cn; Tel.: +86-531-8963-1206
}

Received: 21 September 2018; Accepted: 29 October 2018; Published: 2 November 2018

\begin{abstract}
Transparent nanocomposite films containing quantum dots are popular because of their extensive applications. However, nanoparticles tend to aggregate, resulting in phase separation of the nanoparticles in the polymer matrix. Herein, we present a bulk thermo-curing copolymerization method to fabricate poly(methyl methacrylate)-based nanocomposite films with ultra-high-loading $\mathrm{ZnS}$ quantum dots (ZnS/PMMA), utilizing polymerizable group-capped $\mathrm{ZnS}$ and monomer of methyl methacrylate (MMA). We found that the nanocomposite film is highly transparent, although the transmittance decreases with the ZnS content, especially at the wavelength between $300 \mathrm{~nm}$ and $400 \mathrm{~nm}$. The results from X-ray diffraction (XRD), transmission electron microscopy (TEM), and dynamic mechanical thermal analysis (DMTA) show that the ZnS quantum dots maintain their original crystal structure, and are uniformly dispersed in the nanocomposite films, even with a very high $\mathrm{ZnS}$ content (41 wt \%, determined by thermogravimetric analysis). The thermogravimetric analysis shows that the nanocomposite films possess a better thermal stability than that of pure PMMA film. The photoluminescence measurements show that $\mathrm{ZnS} / \mathrm{PMMA}$ nanocomposite films have good optical properties. The fluorescence intensity increases with the increment of free $\mathrm{ZnS}$ content to $30 \mathrm{wt} \%$, and then decreases due to self-reabsorption at a higher ZnS content. The transparent ZnS/PMMA nanocomposite films have a potential application as photoluminescence material.
\end{abstract}

Keywords: nanocomposites; Quantum dots; poly(methyl methacrylate); photoluminescence

\section{Introduction}

Quantum dots (QDs) possess attractive properties, such as narrow tunable emission and a high photoluminescence quantum yield (PLQY), making them promising candidates for numerous applications, including light-emitting diodes (LEDs) [1], photodetectors [2], biological labeling and imaging [3,4], lasers [5], and energy harvesting [6]. However, quantum dots are sensitive to moisture and oxygen, and tend to aggregate as a result of their highly specific surface energies. Incorporation of quantum dots in the polymer material can improve its stability, because the aggregation can be blocked by polymers among nanoparticles, and moisture can be prevented by the polymer matrices, especially hydrophobic ones. Moreover, the incorporation of inorganic quantum dots can endow the materials' new or largely enhanced properties.

Many efforts have been made to develop QDs/polymer nanocomposite films. Quantum dots possess unique size-dependent properties; therefore, it is critical to control the nanoparticle size and size distribution, as well as the dispersion homogeneity in the polymer matrix. Two main approaches have been developed to fabricate nanocomposite films' incorporated quantum dots, including either 
in-situ nanoparticle formation [7] or the bulk polymerization of monomer solution to fill premade quantum dots. Obviously, the latter approach is usually more advantageous because of the controllable size and size distribution of premade quantum dots, enlarging their unique size-dependent properties. Unfortunately, quantum dots also tend to aggregate in the process of bulk polymerization, resulting in severe optical scattering and reduced transmittance of the nanocomposites. This will decrease the photoluminescence quantum yield of quantum dots to UV irradiation. To our knowledge, usually only a small amount of quantum dots (usually less than $10 \mathrm{wt} \%$ ) can be incorporated in the nanocomposite films without sacrificing material properties resulting from aggregation. Researchers used to think that incorporation of a small amount of QDs is enough for photoluminescence, because self-reabsorption usually happens when the content of quantum dots is high in the nanocomposite films. However, according to a recent study by Chao Liu et al. [8], self-reabsorption can be alleviated by adding organic dyes with large Stokes shifts and great absorption at QD emission wavelengths that help extract QD-borne excitons for photon production. They prepared ultra-high-loading quantum/polymer nanocomposites with lower-band-gap organic dyes, resolving the problem of severe light yield deterioration, and the nanocomposite films exhibited simultaneous improvements in both light yield and gamma attenuation. Therefore, it is important to fabricate uniform nanocomposite films with high-loading quantum dots. Moreover, our previous work $[9,10]$ shows that high incorporation of ZnS QDs helps to improve the refractive index of nanocomposites. We grafted polymerizable molecules on the surface of a $\mathrm{ZnS}$ quantum dot, and then the high content of $\mathrm{ZnS}$ was pendant onto the polymer backbone by copolymerization with monomers of 2-hydroxyethyl methacrylate (HEMA) and $\mathrm{N}, \mathrm{N}$-dimethylformamide (DMA). The true $\mathrm{ZnS}$ content determined by thermogravimetric analysis can be improved to $50 \mathrm{wt} \%$, and the nanocomposite is high transparent. The incorporation of the high content of $\mathrm{ZnS}$ greatly improves its refractive index.

Poly(methyl methacrylate) (PMMA) is a key polymer component for nanocomposite films, with wide applications in many technological and productive fields, which take advantage of its unique properties, including excellent transmittance from the near UV to the near IR [11], good mechanical properties, thermal stability, low dielectric constant, and moisture resistance. In particular, its moisture resistance can block the contact of water to quantum dots in the nanocomposite, making it more stable. Low UV absorption of a PMMA matrix helps more energy be absorbed by quantum dots under UV irradiation, maintaining the photophysics associated with the photoexcited states of the crystallites in the nanocomposites.

Many kinds of quantum dots—e.g., ZnO [12], CdTe [13], ZnS [14], and (CdSe)ZnS [15]—have been incorporated in PMMA-based materials, either by being embedded physically in the polymer matrices by weak interactions, through hydrogen bonding or Van der Waals interactions, or strongly linked through the formation of covalent or ionic bonds with polymer backbones [16]. However, the nanoparticle content in the nanocomposites is usually low, and it is still a huge technological challenge in the fabrication of transparent PMMA-based nanocomposites with high quantum dot content. In this work, we grafted polymerizable molecules onto the surface of a quantum dot of ZnS, and then prepared high-ZnS-loading, PMMA-based nanocomposites by bulk copolymerization between polymerizable group-capped ZnS and MMA monomers. The ZnS nanoparticle can be dispersed uniformly in the nanocomposite films, resulting in the ZnS/PMMA nanocomposite films being highly transparent, even with ultra-high-loading ZnS. The effect of ZnS incorporation into the nanocomposites on the material characterization was also studied, indicating a potential application as photoluminescence material.

\section{Experimental Part}

\subsection{Materials}

Zinc acetate dihydrate and thiourea were purchased from Damao Chemicals (Tianjin, China). Mercaptoethanol (ME), 2-isocyanatoethyl methacrylate (IEM), and dibutyltin dilaurate (DBTDL) were 
purchased from Aladdin Chemical Reagent Co., Ltd. (Shanghai, China). Methyl methacrylate (MMA) and azobisisobutyronitrile (AIBN) were purchased from SA Chemical Technology Co., Ltd. (Shanghai, China).

\subsection{Synthesis of Polymerizable Group-Capped ZnS Nanoparticles}

Polymerizable-group-capped ZnS nanoparticles (NPs) were synthesized according to our previous work [9]. Briefly, $\mathrm{Zn}(\mathrm{Ac})_{2} \cdot 2 \mathrm{H}_{2} \mathrm{O}(11.0 \mathrm{~g}, 0.05 \mathrm{~mol})$, $\mathrm{ME}(5.8 \mathrm{~g}, 0.074 \mathrm{~mol})$, thiourea $(2.75 \mathrm{~g}, 0.036 \mathrm{~mol})$, and DMF (150 mL) were added to a $25 \mathrm{~mL}$ three-necked round-bottom flask equipped with a magnetic stirrer, a condenser, and nitrogen purging. The solution was refluxed at $160{ }^{\circ} \mathrm{C}$ for $10 \mathrm{~h}$ under continuous stirring and nitrogen purging. The resultant mixture was concentrated and then precipitated, using excess ethanol to obtain ME-capped $\mathrm{ZnS}$ nanoparticles. ME-capped $\mathrm{ZnS}$ in the amount of $3 \mathrm{~g}$ and one drop of DBTDL were dispersed in $75 \mathrm{~mL}$ DMF solution to obtain a clear solution, in which a DMF solution of 2-isocyanatoethyl methacrylate (IEM) (0.45 g in $15 \mathrm{~mL}$ DMF) was added into the DMF solution of ME-capped ZnS nanoparticles drop by drop by a constant pressure drop funnel. The solution was kept at $30^{\circ} \mathrm{C}$ for $2.5 \mathrm{~h}$, and then precipitated in excess methanol. The solid precipitation (named as $\mathrm{ZnS}_{0.15}$, as the subscript of 0.15 corresponds to the $0.15 \mathrm{~g}$ amount of added IEM per gram of ME-capped ZnS) was collected and washed with methanol before being dried in vacuum at $30^{\circ} \mathrm{C}$.

\subsection{Preparation of Transparent ZnS/Poly(methyl methacrylate) Nanocomposite Films}

The ZnS/PMMA nanocomposite films were prepared by a bulk thermo-curing copolymerization approach. Firstly, $\mathrm{ZnS}_{0.15}$, with the formulations as described in Table 1, was dispersed in DMF by ultrasound, and then the monomer of MMA and $0.5 \mathrm{wt} \%$ initiator of AIBN were added to obtain homogeneous polymerization solution. Finally, the polymerization solution was injected into the cavity of the polypropylene plate mold, separated by a polypropylene frame with a controlled thickness, and then cured at $80^{\circ} \mathrm{C}$ for $12 \mathrm{~h}$ to obtain transparent PMMA-based nanocomposite films.

Table 1. Formulations of transparent poly(methyl methacrylate) (PMMA)-based nanocomposites.

\begin{tabular}{ccccc}
\hline Samples & The Free Content of $\mathbf{Z n S}_{\mathbf{0 . 1 5}}$ & $\mathbf{Z n S}_{\mathbf{0 . 1 5}} \mathbf{( g )}$ & Monomer of MMA (g) & Solvent of DMF(g) \\
\hline 1 & $10 \mathrm{wt} \%$ & 0.05 & 0.45 & 0.3 \\
2 & $30 \mathrm{wt} \%$ & 0.15 & 0.35 & 0.3 \\
3 & $50 \mathrm{wt} \%$ & 0.25 & 0.25 & 0.3 \\
4 & $70 \mathrm{wt} \%$ & 0.35 & 0.15 & 0.3 \\
\hline
\end{tabular}

\subsection{Characterization of ZnS/Poly(methyl methacrylate) Nanocomposite Films}

\subsubsection{X-ray Diffraction}

X-ray diffraction (XRD) data of ME-capped ZnS, polymerizable group-capped nanoparticles, and ZnS/PMMA nanocomposites were recorded on a Bruker AXS D8 X-ray diffractometer (Rheinstetten, Germany) with a $\mathrm{Cu} \mathrm{K} \alpha(\lambda=1.5406 \AA)$ source, operated at $40 \mathrm{kV}$ and $20 \mathrm{~mA}$ at $293 \mathrm{~K}$. The $2 \theta$ scanning range was from $10^{\circ}$ to $90^{\circ}$, with a step size of $0.02^{\circ}$ and at a scanning speed of 1 degree $/ \mathrm{min}$.

\subsubsection{Transmission Electron Microscopy}

ZnS/PMMA nanocomposite films were embedded in Epon 812 epoxy resin, and then polymerized overnight at $60{ }^{\circ} \mathrm{C}$. Ultrathin sections were cut using a Boeckeler Power Tome XL microtome (Tucson, AZ, USA). Cross-sections of the nanocomposite films were observed and photographed using a JEM-2100 transmission electron microscope (Tokyo, Japan). ME-capped ZnS and polymerizable group-capped nanoparticles were also observed with JEM-2100. 


\subsubsection{Dynamic Mechanical Thermal Analysis}

The nanocomposite films were cut into $5 \times 30 \mathrm{~mm}^{2}$ rectangular bars, and their dynamic mechanical behaviors were recorded on a Tritec 2000 (Hayward, CA USA) instrument in a single cantilever bending mode. A storage modulus $\left(\mathrm{E}^{\prime}\right)$ and $\tan \delta$ were registered as a dependence on temperature ranging from 0 to $250{ }^{\circ} \mathrm{C}$, using a $5{ }^{\circ} \mathrm{C} / \mathrm{min}$ heating rate at a frequency of $1 \mathrm{~Hz}$.

\subsubsection{Thermogravimetric Analysis}

ME-capped ZnS, polymerizable group-capped ZnS NPs, as well as the nanocomposite films in the dry state were sealed in aluminum pans, and then thermogravimetric analysis (TGA) was performed using a SDT-Q600 TGA instrument (New Castle, DE, USA) at a heating rate of $10^{\circ} \mathrm{C} / \mathrm{min}$ in the temperature range from ambient to $600{ }^{\circ} \mathrm{C}$ in a nitrogen gas purge.

\subsubsection{Light Absorption/Transmittance Spectra}

ME-capped and polymerizable-group-capped ZnS were dispersed in DMF under ultrasound to obtain a clear and uniform solution with a concentration of $10 \mathrm{mg} / \mathrm{mL}$. The nanocomposite films were cut into $10 \times 40 \mathrm{~mm}^{2}$ strips and placed vertically in the light road. Transmittance and absorption of the nanocomposite films were recorded at wavelengths from 200 to $800 \mathrm{~nm}$ with a UV-Vis spectrophotometer (He入ios, Thermo Electro, Cambridge, UK), using the air as a reference. The transmittance and absorption of ME-capped and polymerizable group-capped ZnS were determined using DMF as a reference at the same wavelength range.

\subsubsection{Photoluminescence Spectra}

Photoluminescence (PL) spectra of ME-capped and polymerizable group-capped ZnS NPs and ZnS/PMMA nanocomposite films were measured on a VARIAN Cary Eclipse fluorescence spectrophotometer (Lake Forest, CA, USA) with an Xe-lamp as the excitation source, the tube voltage at $600 \mathrm{~V}$, and excitation and emission slits of $5 \mathrm{~nm}$.

\section{Results and Discussion}

The synthesis route of transparent high QD-loading nanocomposite films was shown in Scheme 1. A multi-hydroxyl group on the surface of ME-capped ZnS, from tightly absorbing mercaptoethanol, endows grafting sites for polymerizable molecule. Polymerizable group-capped $\mathrm{ZnS}$ was synthesized by a partial chemical graft of the hydroxyl on the surface of $\mathrm{ZnS}$ by 2-isocyanatoethyl methacrylate. ME-capped and polymerizable group-capped $\mathrm{ZnS}$ can be well-dispersed in DMF to obtain a clear solution. High-resolution transmission electron microscopy (HRTEM) photography, as shown in Figure 1, indicates that the nanoparticle diameter is about $3 \mathrm{~nm}$ with a uniform size distribution. The lattice fringes with a distance of $0.294 \mathrm{~nm}$ can be clearly observed, indicating that the grafting reaction of the polymerizable molecules on the $\mathrm{ZnS}$ surface do not influence the crystalline structure of ZnS NPs. This is important for the quantum dot to maintain its attractive properties, such as tunable emission, high photoluminescence quantum yield, and high refractive index. According to Rayleigh's law, light scattering of the spherical particles in the nanocomposite films leads to an intensity loss that can be calculated as follows:

$$
I=I_{0} \exp \left[-\frac{3 \phi l R^{3}}{4 \lambda^{4}}\left(\frac{n_{N P}}{n_{p}}-1\right)\right]
$$

where $I_{0}$ and $I$ are the intensity of the incident and transmitted light, respectively; $\phi$ is the volume fraction of the particles; $l$ refers to the thickness of the nanocomposite film; and $\lambda$ is the wavelength of the incident light. The variables $n_{N P}$ and $n_{P}$ are the refractive index of nanoparticles and the polymer matrix in the nanocomposite films, respectively. It can be concluded from Equation (1) that the size of the nanoparticles in the nanocomposite films has a much stronger effect on the transmittance than the film thickness. Generally, the upper limit of the nanoparticle size is about $40 \mathrm{~nm}$ for transparent 
nanocomposite film, to avoid the loss of transmitted light from scattering. The refractions of PMMA and quantum dot $\mathrm{ZnS}$ are about 1.5 and 2.3, respectively. The volume fraction of the $\mathrm{ZnS}$ nanoparticles can be calculated by the weight percent of added $\mathrm{ZnS}_{0.15}$ in the nanocomposite, capping the amount of ME on the surface of the $\mathrm{ZnS}(37.05 \mathrm{wt} \%)$ and the densities of pure $\mathrm{ZnS}\left(4.1 \mathrm{~g} \mathrm{~cm}^{-3}\right)$, the capping agent of ME $\left(1.11 \mathrm{~g} \mathrm{~cm}^{-3}\right)$, and PMMA matrices $\left(1.18 \mathrm{~g} \mathrm{~cm}^{-3}\right)$. The volume fraction of ZnS NPs in the nanocomposite with $70 \mathrm{wt} \%$ content of $\mathrm{ZnS}_{0.15}$ is about $27 \%$, and the thickness of the nanocomposite film is about $700 \mu \mathrm{m}$. It can be predicted that less than $1 \%$ of the incident light intensity will be lost because of the scattering of ZnS NPs in the nanocomposite films. Therefore, nanoparticle aggregation will be a considerable factor affecting transmittance of nanocomposite films.

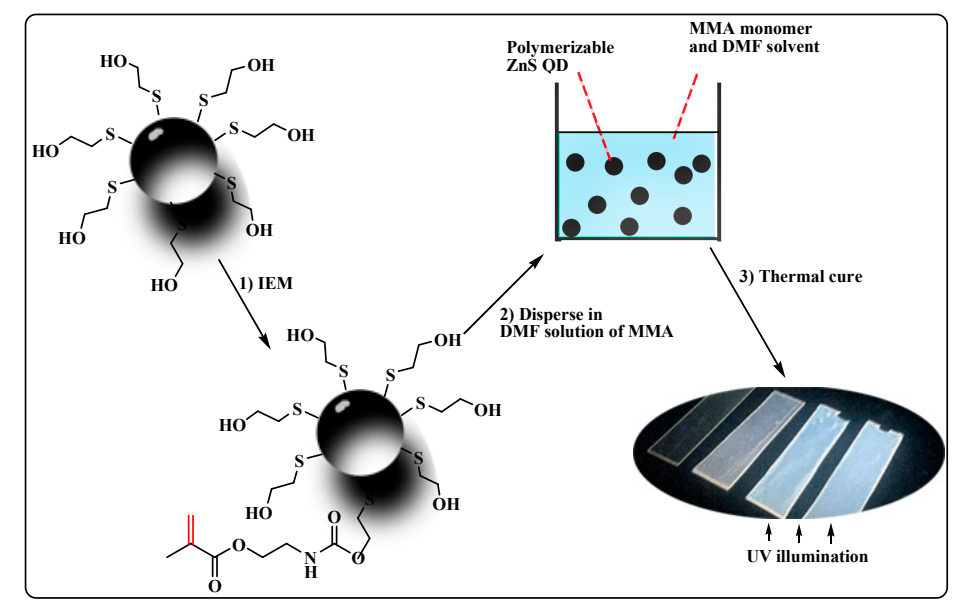

Scheme 1. Schematic illustration of the partial chemical graft of polymerizable molecules on the mercaptoethanol (ME)-capped ZnS surface and the bulk copolymerization process of poly(methyl methacrylate)-based nanocomposite films with ultra-high-loading ZnS quantum dots (ZnS/PMMA). IEM is an abbreviation of 2-Isocyanatoethyl methacrylate, and MMA means a monomer of methyl methacrylate. The last photograph is ZnS/PMMA nanocomposite films under UV illumination (the thickness is $0.7 \mathrm{~mm}$, with a loading free $\mathrm{ZnS}_{0.15}$ quantum dots (QDs) varying from $10 \mathrm{wt} \%$ to $70 \mathrm{wt} \%$, at a $20 \mathrm{wt} \%$ increment from left to right).

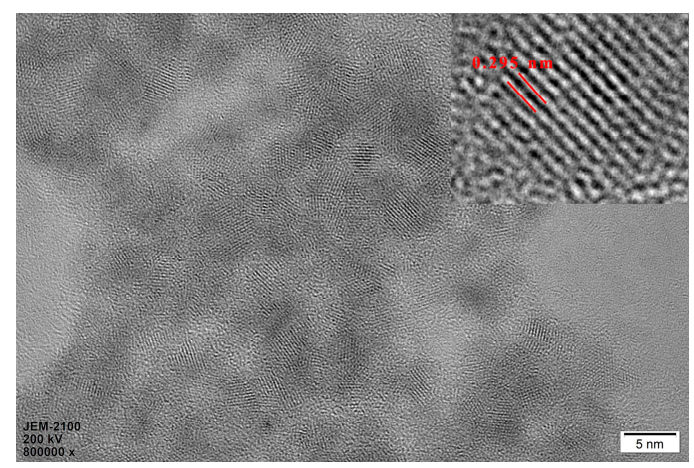

Figure 1. High-resolution transmission electron microscopy (HRTEM) photography of polymerizable group-capped $\mathrm{ZnS}_{0.15}$.

The solvent of DMF was used in the preparation of the nanocomposite films, because polymerizable group-capped ZnS nanoparticles cannot disperse in the monomer of MMA. In the bulk thermo-curing copolymerization strategy, all reagents were mixed together as follows: polymerizable $\mathrm{ZnS}_{0.15}$ was dispersed in the DMF solvent, and then the monomer of MMA and initiator of AIBN were added under ultrasonic dispersion to form a clear and uniform polymerizable solution. After $12 \mathrm{~h}$ curing at $80^{\circ} \mathrm{C}$, the nanocomposite films were transparent, as shown in the inserted photograph in Figure 2. We also prepared a nanocomposite film by physically embedding ME-capped ZnS NPs, 
which were opaque, even decreasing the ME-capped $\mathrm{ZnS}$ less than $5 \mathrm{wt} \%$, although the polymerizable solution was also clear and uniform. This indicates that the difference between ME-capped ZnS nanoparticles and the MMA monomers was enlarged during the polymerization of monomers into a polymer. The attachment of ZnS NPs onto the polymer backbone by copolymerization between polymerizable $\mathrm{ZnS}_{0.15}$ and the monomer of MMA blocks the microphase separation of $\mathrm{ZnS}$ NPs from the PMMA matrix, to which the enlarged difference can be ascribed.

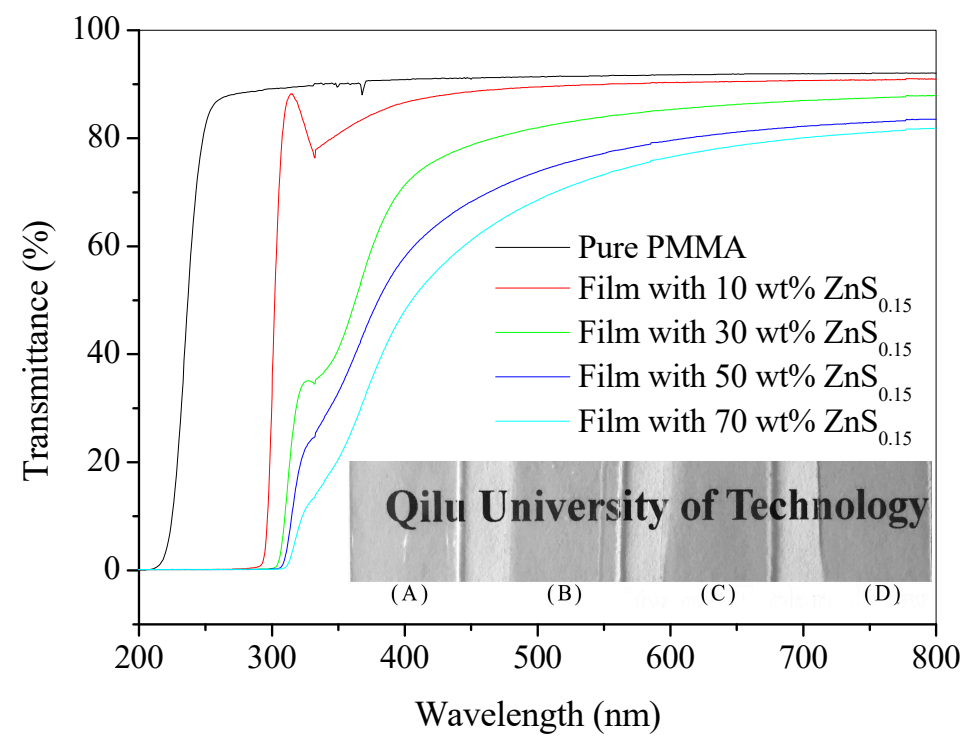

Figure 2. Transmittance spectra of $\mathrm{ZnS} / \mathrm{PMMA}$ nanocomposite films, with different free $\mathrm{ZnS}_{0.15}$ content. The inserted photograph is the appearance of ZnS/PMMA nanocomposite films with a free $\mathrm{ZnS}_{0.15}$ content of (A) $10 \mathrm{wt} \%$, (B) $30 \mathrm{wt} \%$, (C) $50 \mathrm{wt} \%$, and (D) $70 \mathrm{wt} \%$ (sample thickness: $0.7 \mathrm{~mm}$ ).

Pure PMMA film shows high transparency between 250 and $800 \mathrm{~nm}$; while the nanocomposite films with high $\mathrm{ZnS}$ content are transparent, the incorporation of $\mathrm{ZnS}$ in the nanocomposite films decreases its transmittance, especially at the wavelength ranging from $300 \mathrm{~nm}$ to $400 \mathrm{~nm}$, as shown in Figure 2. This indicates that the $\mathrm{ZnS}$ nanoparticle in the nanocomposite films has a strong absorption. The transmittance of the nanocomposite film with a free $\mathrm{ZnS}_{0.15}$ content of $10 \mathrm{wt} \%, 30 \mathrm{wt} \%, 50 \mathrm{wt} \%$, or $70 \mathrm{wt} \%$ is respectively about $90 \%, 84 \%, 77 \%$, or $74 \%$ at the wavelength of $555 \mathrm{~nm}$, which is the most sensitive wavelength for human eye and corresponds to yellow and green light [17]. This indicates that $\mathrm{ZnS}$ nanoparticles disperse uniformly in the nanocomposite films. However, it seems that the transmittance is much less than that predicted by Rayleigh's law, indicating possible slight aggregation of ZnS NPs in nanocomposite film with high content of ZnS.

To get further information on the dispersibility of ZnS NPs in the nanocomposites, the ultrathin sections of the nanocomposite films were observed using transmission electron microscopy (TEM). The nanocomposite film embedded in physically ME-capped ZnS NPs clearly exhibits serious particle aggregation, resulting in irregular phase separation, as shown in Figure 3A. Phase separation will cause optical scattering and reduce transmittance, in good agreement with the opaque appearance of ME-capped ZnS embedded physically in nanocomposite film. The TEM photographs of the nanocomposite films from copolymerization between $10-70 \mathrm{wt} \%$ polymerizable group-capped $\mathrm{ZnS}_{0.15}$ and the monomer of MMA were shown in Figure 3B-E. Although no obvious ZnS NP was observed in the nanocomposite film with $10 \mathrm{wt} \% \mathrm{ZnS}_{0.15}$, $\mathrm{ZnS}$ NPs can be clearly observed when the free $\mathrm{ZnS}_{0.15}$ content increased to $30 \mathrm{wt} \%$. It can be seen that the nanocomposite films copolymerized from $\mathrm{ZnS}_{0.15}$ and the monomer of MMA can remarkably block $\mathrm{ZnS}$ aggregation in resulting nanocomposites. However, slight aggregation of ZnS NPs can still observed, resulting from the phase domain (about $6 \mathrm{~nm}$ ) that is larger than the size of $\mathrm{ZnS}$ quantum dot, as shown in Figure 3C. Figure 3D-E shows a higher nanoparticle content, and the phase domain from aggregation seems to be bigger as the $\mathrm{ZnS}$ 
content increases in the nanocomposite films. This can be seen clearly in Figure 3E, in good agreement with the decreased transmittance shown in Figure 2.
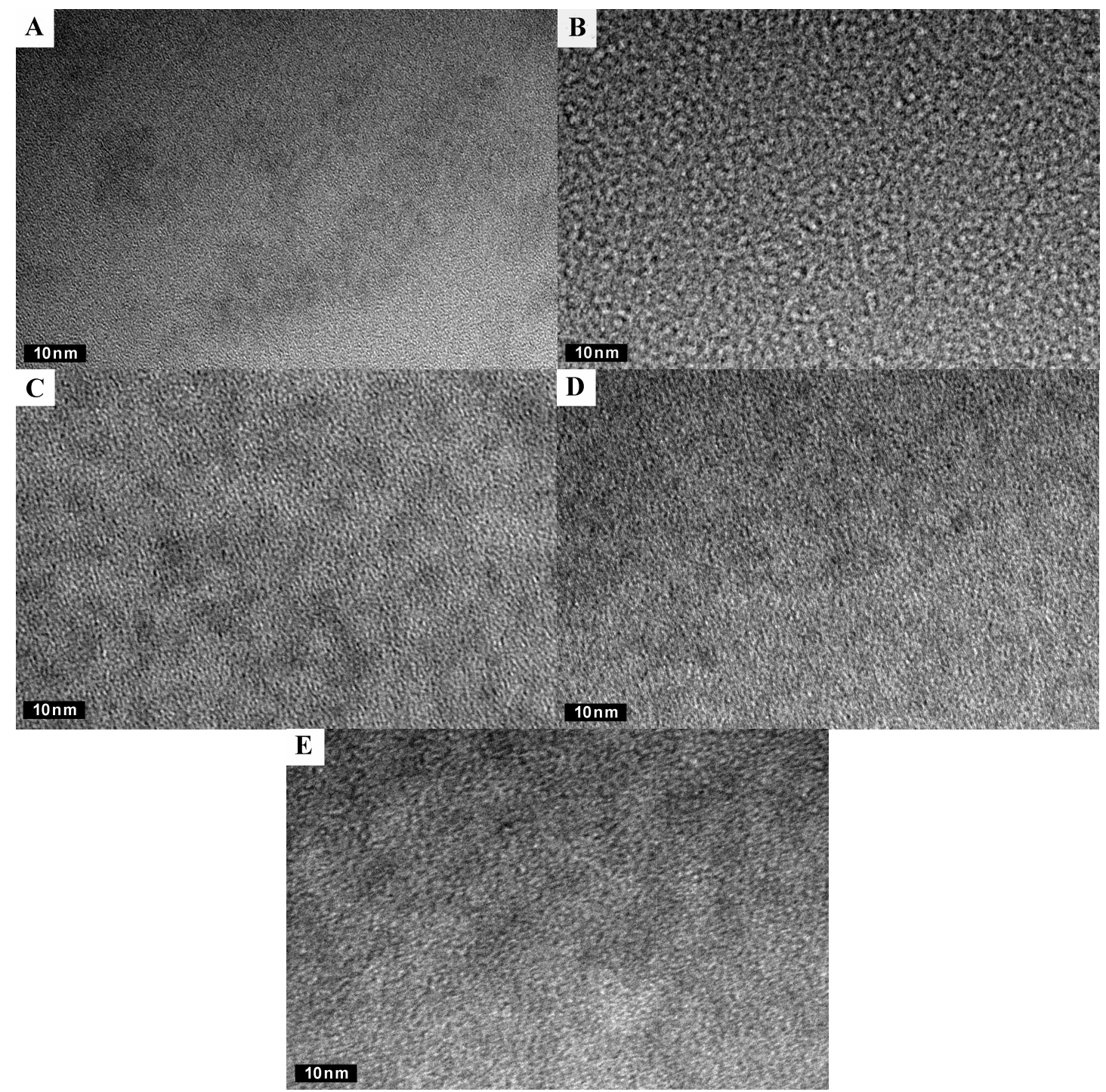

Figure 3. Transmission electron microscopy (TEM) photography of (A) ZnS/PMMA nanocomposite films embedded physically into ME-capped ZnS and ZnS/PMMA co-polymerizable nanocomposite films with the following different content levels of free $\mathrm{ZnS}_{0.15}$ : (B) $10 \mathrm{wt} \%$, (C) $30 \mathrm{wt} \%$, (D) $50 \mathrm{wt} \%$, and (E) $70 \mathrm{wt} \%$.

The X-ray diffraction (XRD) patterns of polymerizable $\mathrm{ZnS}_{0.15}$ and the nanocomposite film with different content $\mathrm{ZnS}_{0.15}$ are shown in Figure 4. It can be seen that three diffraction peaks are observed at $28.5^{\circ}, 47.6^{\circ}$, and $56.4^{\circ}$, corresponding to the (111), (220), and (311) planes of ZnS with a zinc blend structure [18]. This indicates that the crystal structure and crystallinity are not affected by the grafting reaction of polymerizable molecules on the surface of ME-capped ZnS NP and the copolymerization reaction between polymerizable $\mathrm{ZnS}_{0.15}$ and the MMA monomer. The size of the $\mathrm{ZnS}$ nanoparticle in the nanocomposite film is also about $3.0 \mathrm{~nm}$, calculated by Scherrer's formula $(d=k \lambda / \beta \cos \theta)$ based on the (111) peak, in good agreement with the nanoparticle size observed from TEM. Moreover, the nanocomposite films show another broad peak at $13^{\circ}$ from PMMA matrices, and the peak intensity rapidly decreases with improved $\mathrm{ZnS}$ content in the nanocomposites. 


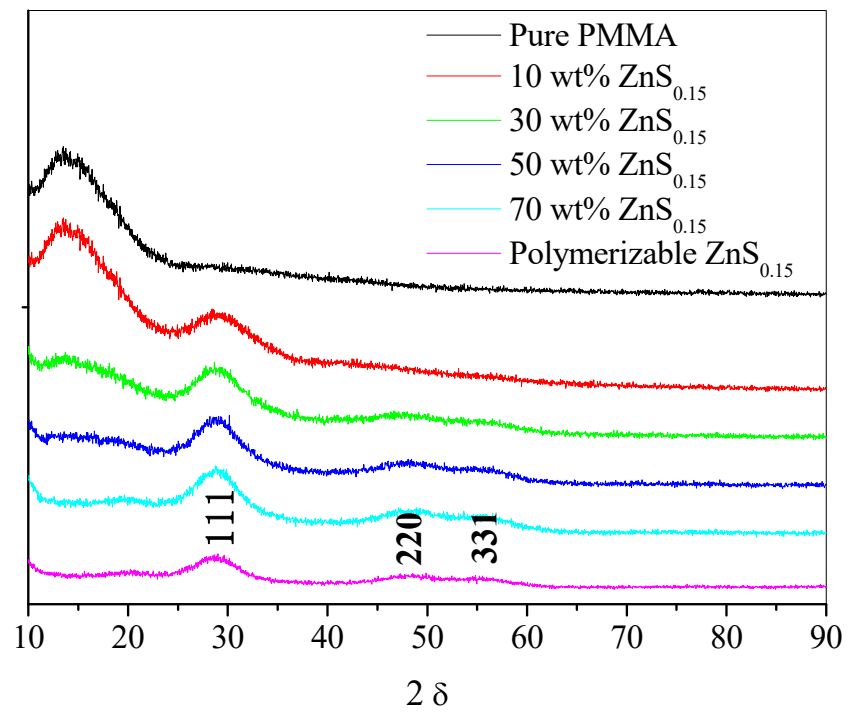

Figure 4. XRD patterns of polymerizable $\mathrm{ZnS}_{0.15}$, pure PMMA film, and the nanocomposite films with different $\mathrm{ZnS}_{0.15}$ content.

To determine the actual content of pure inorganic $\mathrm{ZnS}$ and the thermal stability of ZnS/PMMA nanocomposite films, thermogravimetric analysis of nanocomposite films with different $\mathrm{ZnS}_{0.15}$ content was carried out, compared with the pure PMMA polymer, as well as the ME-capped and $\mathrm{ZnS}_{0.15} \mathrm{NPs}$. TGA curves are shown in Figure 5, and the weight loss at each decomposition step and the residue at $600{ }^{\circ} \mathrm{C}$ are listed in Table 2. Pure PMMA polymer shows a single degradation step at the temperature range of $260-415^{\circ} \mathrm{C}$, owing to the thermo-decomposition of the PMMA polymer, while the ZnS/PMMA nanocomposite films show two obvious degradation steps corresponding to temperature ranges 250-330 ${ }^{\circ} \mathrm{C}$ and $360-470{ }^{\circ} \mathrm{C}$, respectively. ME-capped $\mathrm{ZnS}$ and polymerizable $\mathrm{ZnS}_{0.15}$ show a weight loss at the temperature range of $250-330^{\circ} \mathrm{C}$, similar to the first decomposition temperature range of the nanocomposites, due to the decomposition of the ME molecule on $\mathrm{ZnS}$ surfaces. Therefore, the second temperature range of weight loss should be ascribed to the decomposition of the PMMA component in the nanocomposite films, indicating improved stability of ZnS/PMMA nanocomposite films. This may be explained in that the interaction between the $\mathrm{ZnS}$ nanoparticle and the PMMA polymer matrix is so strong that the thermal degradation of the PMMA polymer is more difficult [19]. The content of pure inorganic $\mathrm{ZnS}$ in ME-capped and polymerizable $\mathrm{ZnS}_{0.15}$ quantum dots is $62.8 \mathrm{wt} \%$ and $63.6 \mathrm{wt} \%$, respectively, indicating the presence of many capping molecules of mercaptoethanol on the nanoparticle surface; only a small number of capping molecules were grafted by the polymerizable molecule. The residue of the nanocomposite films (pure $\mathrm{ZnS}$ ) with free $\mathrm{ZnS}_{0.15}$ content of $10 \mathrm{wt} \%$, $30 \mathrm{wt} \%, 50 \mathrm{wt} \%$, and $70 \mathrm{wt} \%$ is respectively about $13 \mathrm{wt} \%, 28.7 \mathrm{wt} \%, 35.2 \mathrm{wt} \%$, and $41 \mathrm{wt} \%$, in good accordance with the calculated values based on the TGA results of the $\mathrm{ZnS}_{0.15}$ nanoparticle.

Table 2. Weight loss at each decomposition step and the residue at $600{ }^{\circ} \mathrm{C}$.

\begin{tabular}{cccccc}
\hline Samples & $\begin{array}{c}\text { Temperature of } \\
\text { the First Weight } \\
\text { Loss }\left({ }^{\circ} \mathbf{C}\right)\end{array}$ & $\begin{array}{c}\text { Weight } \\
\text { Loss }(\mathbf{w t} \%)\end{array}$ & $\begin{array}{c}\text { Temperature of } \\
\text { the Second } \\
\text { Weight Loss }\left({ }^{\circ} \mathbf{C}\right)\end{array}$ & $\begin{array}{c}\text { Weight } \\
\text { Loss }(\mathbf{w t} \%)\end{array}$ & $\begin{array}{c}\text { The Weight of } \\
\text { Residue at } \mathbf{6 0 0}{ }^{\circ} \mathbf{C}\end{array}$ \\
\hline Pure PMMA & $260-415$ & 89.78 & - & - & 0 \\
NC with 10 wt \% ZnS & $250-330$ & 9.31 & $360-470$ & 62.15 & 12 \\
NC with 30 wt \% ZnS & $250-330$ & 14.04 & $360-470$ & 44.49 & 28.79 \\
NC with 50 wt \% ZnS & $250-330$ & 21.65 & $360-470$ & 27.02 & 35.19 \\
NC with 70 wt \% ZnS & $250-330$ & 25.89 & $360-470$ & 20.74 & 40.96 \\
Polymerizable ZnS ${ }_{0.15}$ & $250-330$ & 24.28 & - & - & 62.95 \\
ME-capped ZnS & $250-330$ & 24.64 & - & - & 63.47 \\
\hline
\end{tabular}




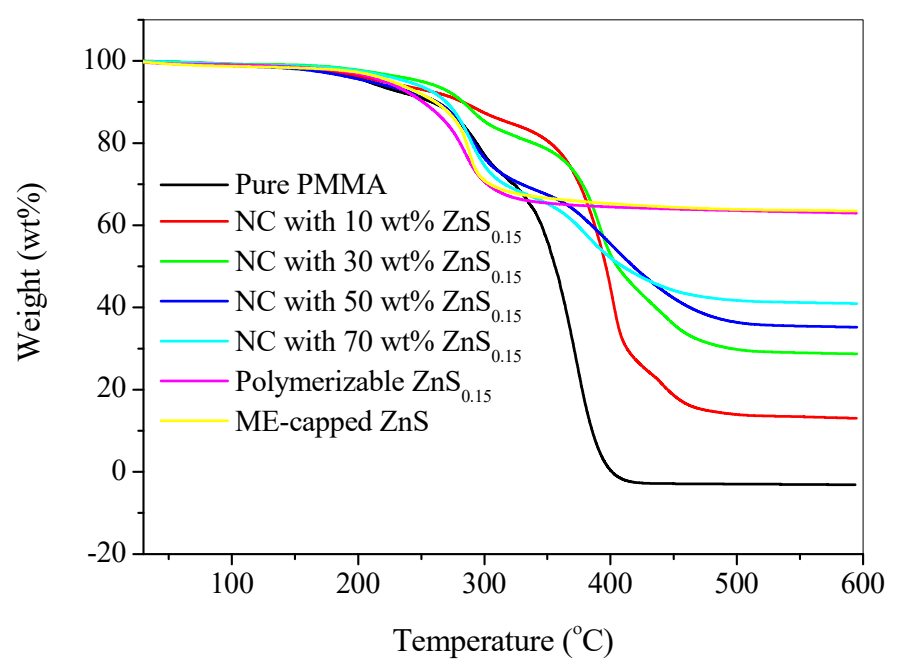

Figure 5. Thermogravimetric analysis (TGA) curves of ME-capped $\mathrm{ZnS}$, polymerizable $\mathrm{ZnS}_{0.15}$, and PMMA-based nanocomposite (NC) films with different $\mathrm{ZnS}_{0.15}$ content. Heating rate is $10{ }^{\circ} \mathrm{C} \mathrm{min}^{-1}$ under $\mathrm{N}_{2}$ flow.

The storage modulus $(E)$ and the loss factor $(\tan \delta)$ of ZnS/PMMA nanocomposite films with different $\mathrm{ZnS}$ content were recorded as a function of temperature. From the viscoelastic curves shown in Figure 6, it can be seen that storage modulus of pure PMMA film is about $2000 \mathrm{MPa}$. Incorporation of a ZnS nanoparticle into PMMA film greatly increases its storage modulus-e.g., increasing to $3165 \mathrm{MPa}$ as $\mathrm{ZnS}$ content increases to $70 \mathrm{wt} \%$. However, pure PMMA film shows the highest amplitude of the damping peak $\left((\tan \delta)_{\max }\right)$ that decreases to 0.62 as the $\mathrm{ZnS}$ content increases to $70 \mathrm{wt} \%$. Moreover, the glass transition temperature $\left(\mathrm{T}_{\mathrm{g}}\right)$, corresponding to the temperature of the maximum of tag $\delta$, increases from $114{ }^{\circ} \mathrm{C}$ to $134{ }^{\circ} \mathrm{C}$. These observations can be explained by improved cross-link density, indicating that more than one hydroxyl on the $\mathrm{ZnS}$ surface is grafted with polymerizable molecule, and polymerizable $\mathrm{ZnS}_{0.15}$ NPs act as a cross-linker in the nanocomposite films.

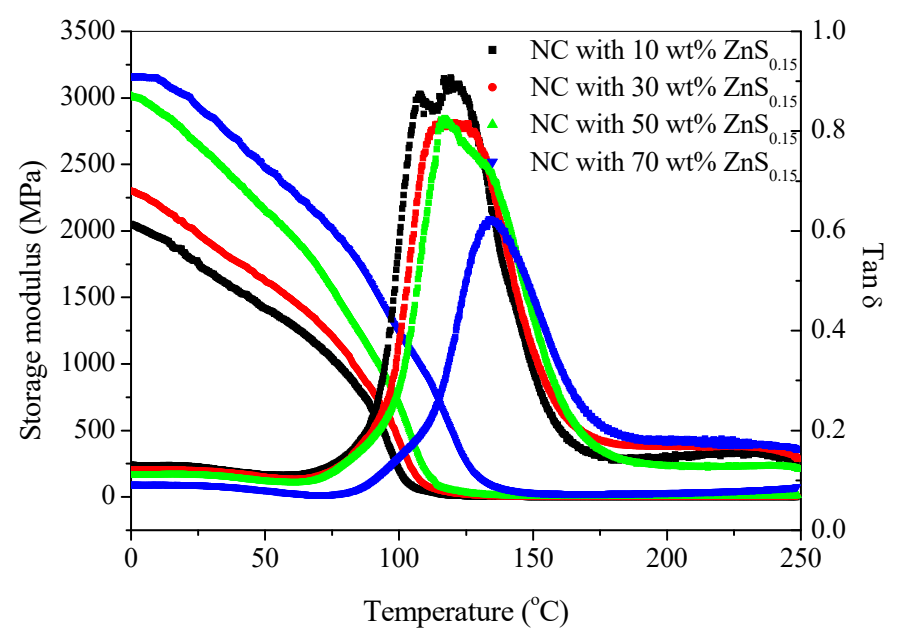

Figure 6. Storage modulus and loss factor $(\tan \delta)$ of ZnS/PMMA nanocomposite films with different $\mathrm{ZnS}_{0.15}$ content.

The loss spectra ( $\tan \delta$ versus temperature) of the ZnS/PMMA nanocomposite films decreases with improved $\mathrm{ZnS}$ content, and all the maximum of $\tan \delta$ are less than 1, differing from pure PMMA film (the maximum of tag $\delta$ is about 1.48). This indicates that the distance between cross-link sites decreases [20], and that nanocomposite films have a higher storage modulus than loss modulus. The widths at the half-height on the relaxation peak are sensitive to the homogeneity of the networks. 
In Figure 6, it is clear that the nanocomposite films exhibited a single glass transition peak, indicating further uniform dispersion of $\mathrm{ZnS}$ in the nanocomposite films as expected.

The UV absorption of ME-capped $\mathrm{ZnS}$, polymerizable $\mathrm{ZnS}_{0.15}$, and the nanocomposite films with different $\mathrm{ZnS}$ content is shown in Figure 7. It can be seen that ME-capped ZnS and polymerizable $\mathrm{ZnS}_{0.15}$ show a similar absorption spectrum, with a maximum absorption centre at $277 \mathrm{~nm}(4.47 \mathrm{eV})$, corresponding to a calculated $\mathrm{ZnS}$ nanoparticle diameter of about $3 \mathrm{~nm}$, according to Brus's model [14]. This value is similar to the particle size observed directly from TEM images shown in Figure 1. The excited state energy $(4.47 \mathrm{eV})$ is larger than a band gap bulk value of $3.66 \mathrm{eV}$ for ZnS. Such a strong and narrow absorption peak at $277 \mathrm{~nm}$ is known to arise from quantum confinement effect, which occurs when the particle size of nanocrystals is comparable with the Bohr radius. Polymerizable $\mathrm{ZnS}_{0.15}$ and $\mathrm{ZnS} / \mathrm{PMMA}$ nanocomposite films show further absorption at $340 \mathrm{~nm}$ $(3.66 \mathrm{eV})$, corresponding to the characteristic absorption peak of $\mathrm{ZnS}$ bulk material, and the intensity of the absorption increases as $\mathrm{ZnS}$ content in the nanocomposite film improves. This indicates that part of ZnS NPs may lose their quantum effect due to aggregation. The exited energy of the quantum dot is inversely related to its particle size [21]. The nanocomposite film with $10 \mathrm{wt} \% \mathrm{ZnS}_{0.15}$ shows a slight blue shift compared to ME-capped $\mathrm{ZnS}$ and polymerizable $\mathrm{ZnS}_{0.15}$. This indicates that the incorporation of $\mathrm{ZnS}$ in the polymer by copolymerization stabilizes nanoparticle size by blocking the aggregation. The luminescent efficiency of the quantum dots increases with decreasing particle size, exhibiting better luminescent properties with smaller QD particle sizes [22]. The maximum absorption wavelength shows a slight redshift with $\mathrm{ZnS}_{0.15}$ increasing content in the nanocomposite films. This indicates that the particle size increases when high $\mathrm{ZnS}$ content is incorporated into the nanocomposite films.

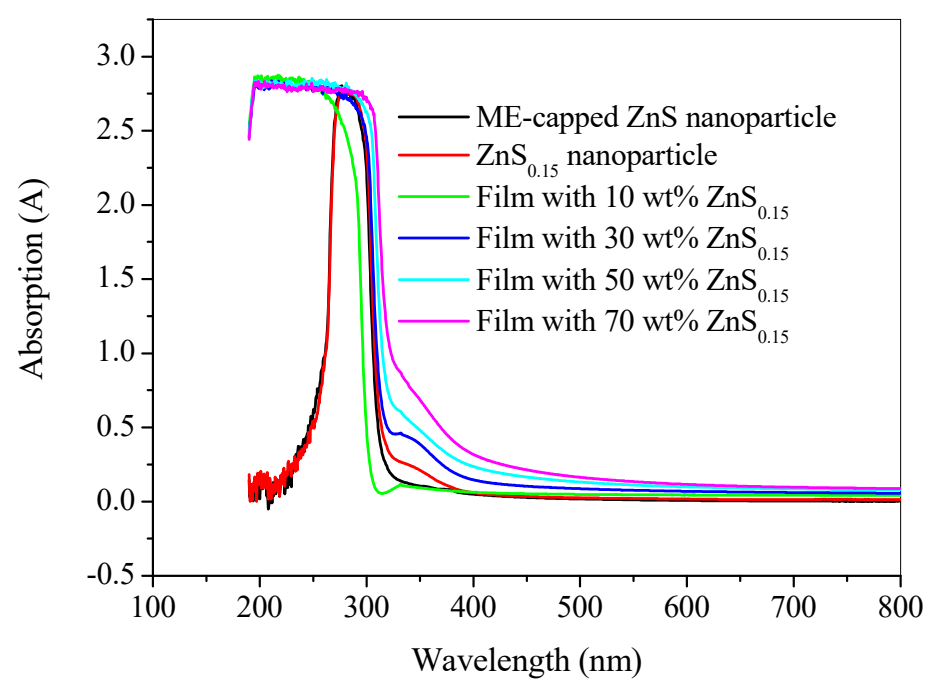

Figure 7. UV absorption spectra of ME-capped $\mathrm{ZnS}$, polymerizable $\mathrm{ZnS}_{0.15}$ and $\mathrm{ZnS} / \mathrm{PMMA}$ nanocomposite films with different $\mathrm{ZnS}_{0.15}$ content.

Figure 8 shows fluorescence photographs of the ZnS/PMMA nanocomposites with different $\mathrm{ZnS}_{0.15}$ content under UV irradiation at a wavelength of $365 \mathrm{~nm}$. No obvious fluorescence was observed for pure PMMA film at an excitation wavelength of $365 \mathrm{~nm}$. However, as a typical semiconductor, $\mathrm{ZnS}$ quantum dots possess interesting fluorescent characteristics that are preserved in the nanocomposite films as expected; the fluorescence intensity seemed to increase when the $\mathrm{ZnS}_{0.15}$ content increases from 0 to $50 \mathrm{wt} \%$. In addition, we found that $\mathrm{ZnS}$ quantum dots are unstable, and their fluorescent intensity decreases greatly after one-day displacement away from light. However, no obvious decrease was observed for the fluorescent intensity of PMMA-based nanocomposite films. This indicates that $\mathrm{ZnS}$ is more stable in PMMA-based matrices than in DMF solution. The emission spectra of ME-capped $\mathrm{ZnS}$ and polymerizable $\mathrm{ZnS}_{0.15}$ dispersed in DMF with a 
concentration $10 \mathrm{mg} / \mathrm{mL}$ are shown as the insert in Figure 9. Usually, redshift in the peak emission wavelength occurs as the concentration of QDs increases due to self-reabsorption and Förster resonance energy transfer (FRET) among neighboring QDs, and becomes more significant as the interparticle distance decreases [23]. The peak emission wavelength $\left(\lambda_{\mathrm{m}} \mathrm{ax}\right)$ redshifts from $390 \mathrm{~nm}$ of ME-capped $\mathrm{ZnS}$ to $430 \mathrm{~nm}$ of polymerizable $\mathrm{ZnS}_{0.15}$, and polymerizable $\mathrm{ZnS}_{0.15}$ has higher fluorescence intensity than that of ME-capped ZnS. The mission behavior exhibits a well-defined excitonic emission feature, consistent with the results for highly luminescent ZnS NPs [24]. The redshift of the peak emission wavelength indicates that polymerizable $\mathrm{ZnS}_{0.15}$ is prone to self-reabsorption and FRET among the QDs, probably because of its different surface ligand. The greater fluorescent intensity of polymerizable $\mathrm{ZnS}_{0.15}$ may be from the annealing effect of the thermal grafting reaction of the polymerizable molecule on an ME-capped ZnS surface, as well as the coverage of surface defects with polymerizable molecule chains [25]. Figure 9 shows the fluorescence emission spectra of the ZnS/PMMA nanocomposite film with excitation at $365 \mathrm{~nm}$. The peak wavelength of characteristic emissions at about $413 \mathrm{~nm}$ is observed for ZnS/PMMA nanocomposite films with 10 and $30 \mathrm{wt} \%$, indicating a minor hypsochromic shift compared with polymerizable $\mathrm{ZnS}_{0.15}$ in DMF. This shift can be explained by an increase in the refractive index of the surrounding matrix [26]. ZnS/PMMA nanocomposite film with $30 \mathrm{wt} \% \mathrm{ZnS}_{0.15}$ shows a higher emission intensity than that with $10 \mathrm{wt} \% \mathrm{ZnS}_{0.15}$; the emission intensity then drops as the $\mathrm{ZnS}_{0.15}$ content increases-e.g., at $50 \mathrm{wt} \%$ and $70 \mathrm{wt} \%$. Moreover, two emission peaks were observed upon the nanocomposite with 50 and $70 \mathrm{wt} \%$, indicating that self-absorption happens at a high ZnS content.
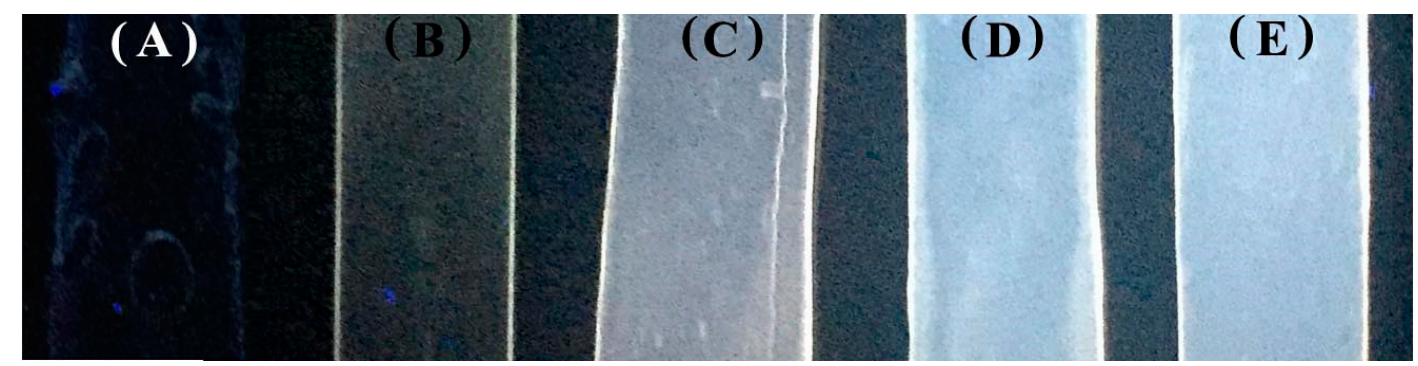

Figure 8. Fluorescence photographs of the $\mathrm{ZnS} / \mathrm{PMMA}$ nanocomposite films with $\mathrm{ZnS}_{0.15}$ of (A) 0 , (B) $10 \mathrm{wt} \%$, (C) $30 \mathrm{wt} \%$, (D) $50 \mathrm{wt} \%$, and (E) $70 \mathrm{wt} \%$ under UV irradiation at a wavelength of $365 \mathrm{~nm}$.

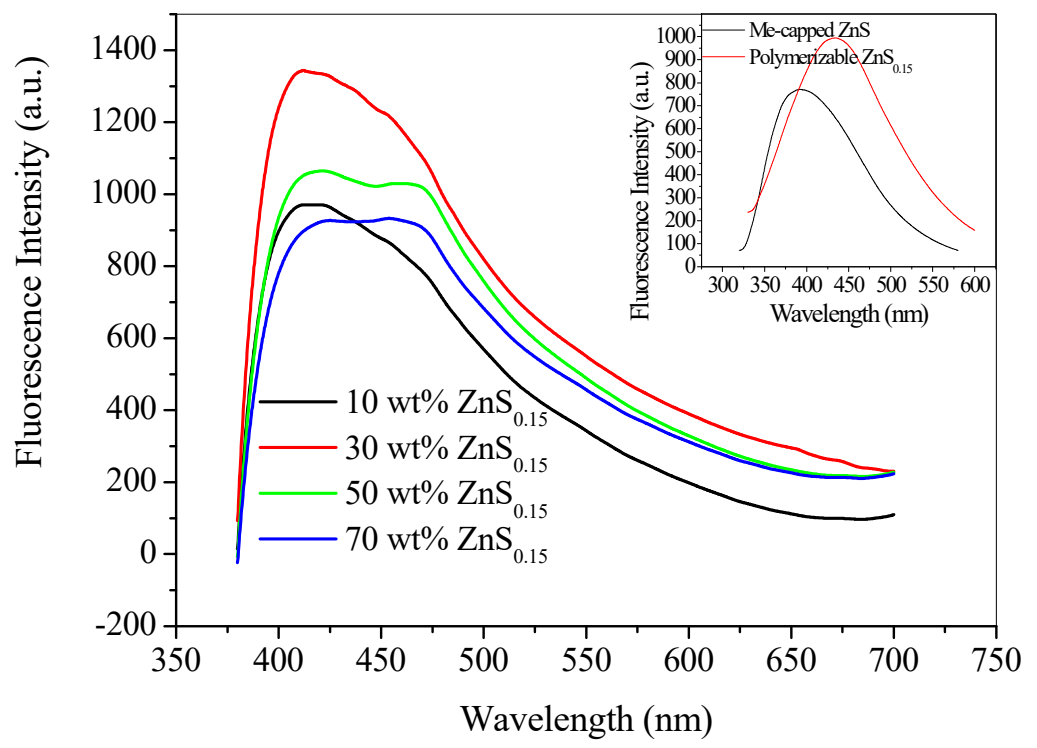

Figure 9. Photoluminescence emission spectra of ME-capped $\mathrm{ZnS}$, polymerizable $\mathrm{ZnS}_{0.15}$, and nanocomposite films with different levels of $\mathrm{ZnS}$ content. 


\section{Conclusions}

ME-capped ZnS quantum dots were synthesized, after which a polymerizable molecule of 2-isocyanatoethyl methacrylate (IEM) was chemically grafted onto the ZnS surface, in order to synthesize polymerizable group-capped $\mathrm{ZnS}$. Furthermore, transparent nanocomposite films with ultra-high-loading ZnS nanoparticles (up to $41 \mathrm{wt} \%$, determined by TGA) were successfully fabricated by bulk thermo-curing copolymerization between the polymerizable group-capped $\mathrm{ZnS}$ and the monomer of MMA. TEM and XRD analysis indicate that ZnS NP dispersed uniformly in the nanocomposite films and remains in its original crystalline structure of $\mathrm{ME}$ and polymerizable group-capped ZnS. The TGA measurement displays that ZnS/PMMA nanocomposite films possess better thermal stability than a pure PMMA polymer. The UV absorption and transmittance measurement showed that the incorporation of $\mathrm{ZnS}$ in the nanocomposite films slightly decreased its transmittance. However, all nanocomposite films possess strong absorption when the wavelength is between 300 and $400 \mathrm{~nm}$. Luminescent photographs show that ZnS/PMMA nanocomposite films exhibit good optical properties. The fluorescence intensity under UV irradiation increased as ZnS increased in increments to $30 \mathrm{wt} \%$, and then decreased as the $\mathrm{ZnC}$ increased further to $70 \mathrm{wt} \%$ due to self-reabsorption.

Author Contributions: J.X. conceived and designed the experiments; D.L. performed the experiments; J.X. and D.L. analyzed the data; J.X. wrote the paper.

Funding: The project was supported by Natural Science Foundation of Shandong Province (No. ZR2016EMM11).

Conflicts of Interest: The authors declare that they have no conflicts of interest.

\section{References}

1. Coe, S.; Woo, W.K.; Bawendi, M.; Bulović, V. Electroluminescence from single monolayers of nanocrystals in molecular organic devices. Nature 2002, 420, 800-803. [CrossRef] [PubMed]

2. Konstantatos, G.; Howard, I.; Fischer, A.; Hoogland, S.; Clifford, J.; Klem, E.; Levina, L.; Sargent, E.H. Ultrasensitive solution-cast quantum dot photodetectors. Nature 2006, 442, 180-183. [CrossRef] [PubMed]

3. Jaiswal, J.K.; Mattoussi, H.; Mauro, J.M.; Simon, S.M. Long-term multiple color imaging of live cells using quantum dot bioconjugates. Nat. Biotechnol. 2003, 21, 47-51. [CrossRef] [PubMed]

4. Michalet, X.; Pinaud, F.F.; Bentolila, L.A.; Tsay, J.M.; Doose1, S.; Li, J.J.; Sundaresan, G.; Wu, A.M.; Gambhir, S.S.; Weiss, S. Quantum Dots for Live Cells, in Vivo Imaging, and Diagnostics. Science 2003, 307, 538-544. [CrossRef] [PubMed]

5. Artemyev, M.V.; Woggon, U.; Wannemacher, R.; Jaschinski, H.; Langbein, W. Light Trapped in a Photonic Dot: Microspheres Act as a Cavity for Quantum Dot Emission. Nano Lett. 2001, 1, 309-314. [CrossRef]

6. Robel, I.; Subramanian, V.; Kuno, M.; Kamat, P.V. Quantum Dot Solar Cells. Harvesting Light Energy with CdSe Nanocrystals Molecularly Linked to Mesoscopic TiO2 Films. J. Am. Chem. Soc. 2006, 128, 2385-2393. [PubMed]

7. Hu, Y.; Chen, W.; Chen, J.; Zhang, Z. Preparation of ZnS nanocrystals in network of hydrogel. Mater. Lett. 2003, 57, 1312-1316. [CrossRef]

8. Liu, C.; Li, Z.; Hajagos, T.J.; Kishpaugh, D.; Chen, D.; Pei, Q. Transparent ultra-high-loading quantum dot/polymer nanocomposite monolith for gamma scintillation. ACS Nano 2017, 11, 6422. [CrossRef] [PubMed]

9. Xu, J.; Zhang, Y.; Zhu, W.; Cui, Y. Synthesis of Polymeric Nanocomposite Hydrogels Containing the Pendant ZnS Nanoparticles: Approach to Higher Refractive Index Optical Polymeric Nanocomposites. Macromolecules 2018, 51, 2672-2681. [CrossRef]

10. Zhao, P.; Xu, J.; Zhang, Y.; Zhu, W.; Cui, Y. Polymerizable-group capped ZnS nanoparticle for high refractive index inorganic-organic hydrogel contact lens. Mater. Sci. Eng. C 2018, 90, 484-493. [CrossRef] [PubMed]

11. Gross, S.; Camozzo, D.; di Noto, V.; Armelao, L.; Tondello, E. PMMA: A key macromolecular component for dielectric low-j hybrid inorganic-organic polymer films. Eur. Polym. J. 2007, 43, 673-696. [CrossRef]

12. Son, D.I.; You, C.H.; Jung, J.H.; Kim, T.W. Carrier transport mechanisms of organic bistable devices fabricated utilizing colloidal $\mathrm{ZnO}$ quantum dot-polymethylmethacrylate polymer nanocomposites. Appl. Phys. Lett. 2010, 97, 131-144. [CrossRef] 
13. Huang, Y.; Liu, J.; Yu, Y.; Zuo, S. Preparation and multicolored fluorescent properties of CdTe quantum dots/polymethylmethacrylate composite films. J. Alloys Compd. 2015, 647, 578-584. [CrossRef]

14. Guo, L.; Chen, S.; Chen, L. Controllable synthesis of ZnS/PMMA nanocomposite hybrids generated from functionalized ZnS quantum dots nanocrystals. Colloid Polym. Sci. 2007, 285, 1593-1600. [CrossRef]

15. Song, H.; Lee, S. Photoluminescent (CdSe)ZnS quantum dot-polymethylmethacrylate polymer composite thin films in the visible spectral range. Nanotechnology 2007, 18, 055402. [CrossRef]

16. Zhang, G.; Zhang, J.; Yang, B. Fabrication of polymerizable ZnS nanoparticles in N,N-dimethylacrylamide and the resulting high refractive index optical materials. Polym. Chem. 2013, 4, 3963-3967. [CrossRef]

17. Xu, J.; Zhu, W.; Jiang, L.; Xu, J.; Zhang, Y.; Cui, Y. Carbazole-grafted silicone hydrogel with a high refractive index for intraocular lens. RSC Adv. 2015, 5, 72736-72744. [CrossRef]

18. Murakoshi, K.; Hosokawa, H.; Tanaka, N.; Saito, M.; Wada, Y.; Sakata, T.; Mori, H.; Yanagida, S. Phase transition of $\mathrm{ZnS}$ nanocrystallites induced by surface modification at ambient temperature and pressure confirmed by electron diffraction. Chem. Commun. 1998, 3, 321-322. [CrossRef]

19. Aymonier, C.; Bortzmeyer, D.; Thomann, R.; Mülhaupt, R. Poly(Methyl methacrylate)/Palladium Nanocomposites: Synthesis and Characterization of the Morphological, Thermomechanical, and Thermal Properties. Chem. Mater. 2003, 15, 4874-4878. [CrossRef]

20. Nograro, F.F.D.; Llano-Ponte, R.; Mondragon, I. Dynamic and mechanical properties of epoxy networks obtained with PPO based amines/mPDA mixed curing agents. Polymer 1996, 37, 1589-1600. [CrossRef]

21. Brus, L. Electronic wave functions in semiconductor clusters: Experiment and theory. J. Phys. Chem. 1986, 90, 2555-2560. [CrossRef]

22. Bhargava, R.N.; Gallagher, D.; Welker, T. Doped nanocrystals of semiconductors-A new class of luminescent materials. J. Lumin. 1994, 60, 275-280. [CrossRef]

23. Vaidya, S.V.; Couzis, A.; Maldarelli, C. Reduction in Aggregation and Energy Transfer of Quantum Dots Incorporated in Polystyrene Beads by Kinetic Entrapment due to Cross-Linking during Polymerization. Langmuir 2015, 31, 3167-3179. [CrossRef] [PubMed]

24. Yu, J.H.; Joo, J.; Park, H.M.; Baik, Su.; Kim, Y.W.; Kim, S.C.; Hyeon, T. Synthesis of Quantum-Sized Cubic ZnS Nanorods by the Oriented Attachment Mechanism. J. Am. Chem. Soc. 2005, 127, 5662-5670. [CrossRef] [PubMed]

25. Sill, K.; Emrick, T. Nitroxide-Mediated Radical Polymerization from CdSe Nanoparticles. Chem. Mater. 2004, 16, 1240-1243. [CrossRef]

26. Schmitt, J.; Mächtle, P.; Eck, D.; Möhwald, H.; Helm, C.A. Preparation and Optical Properties of Colloidal Gold Monolayers. Langmuir 1999, 15, 3256-3266. [CrossRef] 